Cite this article as: BMJ, doi:10.1136/bmj.39164.568183.AE (published 23 April 2007)

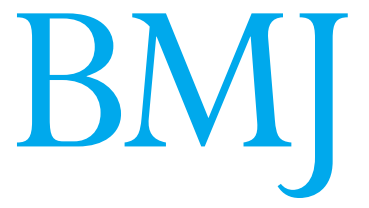

RESEARCH

\title{
Effectiveness of visits from community pharmacists for patients with heart failure: HeartMed randomised controlled trial
}

\begin{abstract}
Richard Holland, senior lecturer in public health medicine, ${ }^{1}$ lain Brooksby, medical director, ${ }^{3}$ Elizabeth Lenaghan, senior research associate, ${ }^{1}$ Kate Ashton, senior research associate, ${ }^{1}$ Laura Hay, specialist registrar in public health medicine, ${ }^{4}$ Richard Smith, reader in health economics, ${ }^{1}$ Lee Shepstone, reader in medical statistics, ${ }^{1}$ Alistair Lipp, director of public health, ${ }^{5}$ Clare Daly, education pharmacist, ${ }^{2}$ Amanda Howe, professor of primary care, ${ }^{1}$ Roger Hall, professor of cardiology, ${ }^{1}$ lan Harvey professor of epidemiology and public health ${ }^{1}$
\end{abstract}

\section{Clinical Trials Unit, School of Medicine, Health Policy and \\ Practice, University of East Anglia, Norwich NR4 7TJ \\ ${ }^{2}$ Academic Pharmacy Practice Unit, University of East Anglia \\ ${ }^{3}$ Norfolk and Norwich University Hospital NHS Trust, Norfolk NR4 7UY \\ ${ }^{4}$ Lothian NHS Board \\ ${ }^{5}$ Great Yarmouth and Waveney Teaching Primary Care Trust, \\ Great Yarmouth, Norfolk, NR14 8AB \\ Correspondence to: $\mathrm{R}$ Holland r.holland@uea.ac.uk}

doi: 10.1136/bmj.39164.568183.AE

\section{ABSTRACT}

Objective To test whether a drug review and symptom self management and lifestyle advice intervention by community pharmacists could reduce hospital admissions or mortality in heart failure patients.

Design Randomised controlled trial.

Setting Home based intervention in heart failure patients. Participants 293 patients diagnosed with heart failure were included (149 intervention, 144 control) after an emergency admission.

Intervention Two home visits by one of 17 community pharmacists within two and eight weeks of discharge. Pharmacists reviewed drugs and gave symptom self management and lifestyle advice. Controls received usual care.

Main outcome measures The primary outcome was total hospital readmissions at six months. Secondary outcomes included mortality and quality of life (Minnesota living with heart failure questionnaire and EQ5D).

Results Primary outcome data were available for 291 participants (99\%). 136 (91\%) intervention patients received one or two visits. 134 admissions occurred in the intervention group compared with 112 in the control group (rate ratio $=1.15,95 \%$ confidence interval 0.89 to 1.48; $\mathrm{P}=0.28$, Poisson model). 30 intervention patients died compared with 24 controls (hazard ratio $=1.18,0.69$ to 2.03; $P=0.54)$. Although EQ-5D scores favoured the intervention group, Minnesota living with heart failure questionnaire scores favoured controls; neither difference was statistically significant.

Conclusion This community pharmacist intervention did not lead to reductions in hospital admissions in contrast to those found in trials of specialist nurse led interventions in heart failure. Given that heart failure accounts for $5 \%$ of hospital admissions, these results present a problem for policy makers who are faced with a shortage of specialist provision and have hoped that skilled community pharmacists could produce the same benefits.

Trial registration number ISRCTN59427925.

\section{INTRODUCTION}

Research on the treatment of heart failure focuses on drug treatment, yet evidence from trials of multidisciplinary interventions suggests that education and drug review interventions are effective at reducing hospital readmission and mortality. ${ }^{1}$ Trials to date have generally used heart failure specialist nurses to deliver these interventions, almost all involved fewer than 200 patients, and most were done outside the United Kingdom, although one of the most positive trials was carried out by specialist nurses in Glasgow. $^{2}$ Unfortunately, few heart failure nurses exist throughout the UK, so developing local packages of specialist care equivalent to that in the Glasgow study may be difficult. ${ }^{2}$ Equally, using hospital based staff in rural areas is likely to be inefficient because of time lost in travel.

Community pharmacists, of whom there are more than 12000 in the UK, provide a possible alternative. They are well placed geographically to provide a local service. They are highly trained in therapeutics, used to dealing with patients on a one to one basis, and skilled in drug problems and adherence. Furthermore, the UK government has been encouraging an extension to the role of community pharmacists, including independent prescribing, medicine use review, and a health promotion role to provide advice about, among other things, smoking cessation and diet. ${ }^{3-5}$ Although pharmacists seem to be an excellent resource with which to provide a Glasgow-style intervention, the only UK evidence to support their use is from two small studies that were limited by their size. ${ }^{67} \mathrm{We}$ have therefore assessed a community pharmacist led intervention in a large randomised controlled trial. 


\section{METHODS}

Recruitment and assignment

Researchers recruited patients from three large district general hospitals. Eligible patients were adults (aged over 18 years), admitted as an emergency in which heart failure was an important ongoing clinical condition, and prescribed two or more drugs (from any drug class) on discharge. We excluded patients if they were living in a residential or nursing home, awaiting surgery for ischaemic or valvular heart disease or heart transplantation, or had terminal malignancy. We randomised patients to receive the pharmacist intervention or usual care. We used third party telephone randomisation based on a computer generated random allocation sequence. We stratified randomisation by New York Heart Association class (class I/II-no or mild limitation, III-moderate limitation, or IVsevere limitation) and recruitment site. We obtained written informed consent from all participants.

\begin{tabular}{|c|c|c|}
\hline Demographic/clinical variables & Intervention group $(n=149)$ & Control group $(n=144)$ \\
\hline Female sex & $54(36.2)$ & $53(36.8)$ \\
\hline Mean (SD) age (years) & $77.6(9.0)$ & $76.4(9.5)$ \\
\hline Living alone & $58(38.9)$ & $52(36.1)$ \\
\hline Mean (SD) abbreviated mental test score* & $9.2(1.0)$ & $9.3(1.0)$ \\
\hline \multicolumn{3}{|l|}{ NYHA class (self classification): } \\
\hline 1 & $6(4.0)$ & $11(7.6)$ \\
\hline II & $43(28.9)$ & $37(25.7)$ \\
\hline III & $52(34.9)$ & $47(32.6)$ \\
\hline IV & $48(32.2)$ & $49(34.0)$ \\
\hline Social class (I, II, IIIN)† & $63(44.1)$ & $76(54.7)$ \\
\hline Mean (SD) No of prescribed items taken daily & $7.9(2.6)$ & $7.7(2.3)$ \\
\hline \multicolumn{3}{|l|}{ Drugs at discharge included: } \\
\hline ACE inhibitor/A2RA & $118(79.2)$ & $109(75.7)$ \\
\hline Loop diuretic & $144(96.6)$ & $140(97.2)$ \\
\hline Spironolactone & $60(40.3)$ & $54(37.5)$ \\
\hline$\beta$ blocker & $53(35.6)$ & $61(42.4)$ \\
\hline Antiarrhythmic & $16(10.7)$ & $19(13.2)$ \\
\hline Warfarin & $51(34.2)$ & $49(34.0)$ \\
\hline Antiplatelet drug & $78(52.3)$ & $76(52.8)$ \\
\hline Digoxin & $52(34.9)$ & $44(30.6)$ \\
\hline Mean (SD) frusemide dose, where applicable (mg) & $88.0(49.0)$ & $87.9(61.6)$ \\
\hline Help with drugs $\ddagger$ & $88(60.3)$ & $76(54.3)$ \\
\hline Drug adherence aid§ & $39(26.5)$ & $22(15.5)$ \\
\hline $\begin{array}{l}\text { Mean (SD) length of stay at baseline (days) (from } \\
\text { HES data) }\end{array}$ & $12.5(16.0)$ & $12.8(12.8)$ \\
\hline $\begin{array}{l}\text { Mean (SD) time from recruitment to discharge } \\
\text { (days) (from HES data) }\end{array}$ & $7.3(15.5)$ & $7.8(11.6)$ \\
\hline $\begin{array}{l}\text { CCU/ICU/HDU admission during baseline } \\
\text { admissionף }\end{array}$ & $11(7.4)$ & $13(9.1)$ \\
\hline
\end{tabular}

$A 2 R A=$ angiotensin-2 receptor antagonist; $A C E=$ angiotensin converting enzyme; $C C U=$ coronary care unit; HES=Hospital Episode Statistics; HDU=high dependency unit; ICU=intensive care unit; NYHA=New York Heart Association.

*Not recorded for one patient in intervention group.

†Employment details not recorded for four patients in each group and not classifiable for two intervention patients and one control patient.

$\ddagger$ Not applicable for three intervention and four control patients who were not taking drugs before their baseline admission.

§Current use of adherence aid not recorded for one patient in each group and not known by one patient in each group.

TNo data for one patient in control group.
Community pharmacists could participate if they held a postgraduate qualification in pharmacy practice or had recent continuing professional development in therapeutics. These pharmacists were not independent prescribers and so could not directly modify patients' drug regimens. All participated in a one day training course, including lectures on heart failure, heart failure drugs, exercise, diet, and smoking cessation advice (contact time $=7$ hours). More than half of the pharmacists attended two evening training events on communication skills (contact time $=4$ hours). Additionally, 14 of the 17 study pharmacists had received training in drug review as part of a previous trial (contact time $=14$ hours). ${ }^{8}$ The other three study pharmacists received an additional one day's training on drug review.

\section{Intervention}

We provided study pharmacists with a copy of the patient's discharge letter. The pharmacist then arranged the home visit, within two weeks of discharge, at a time when they could meet the patient and any carer(s). Where appropriate, pharmacists educated the patient/carer about heart failure and their drugs and gave basic exercise, dietary, and smoking cessation advice. They also encouraged completion of simple sign and symptom monitoring diary cards (including monitoring body weight), removed discontinued drugs (with the patient's consent), fed back recommendations to the general practitioner, and fed back to the local pharmacist any need for a drug adherence aid (for example, a Medidos or Dosett container). We provided all pharmacists with a detailed manual describing the expected components of their visit and asked them to deliver education in line with advice given in the British Heart Foundation's booklet Living with Heart Failure, ${ }^{9}$ which they left with patients after the first visit. Pharmacists completed a standardised visit form during each visit. One follow-up visit occurred at six to eight weeks after discharge to review progress and reinforce original advice. We also recorded a selection of pharmacists' visits to investigate the intervention's delivery and the pharmacists' communication skills. ${ }^{10}$

\section{Masking and the control group}

The nature of the intervention meant that no clear "placebo" could be provided. Participants were told after randomisation which group they were in. Those in the control group received usual care.

\section{Outcome data and analysis}

The primary outcome was total emergency admissions to hospital over six months. Secondary outcomes included deaths and self assessed quality of life measured with the EQ-5D (a generic instrument) ${ }^{11} 12$ and the Minnesota living with heart failure questionnaire (a disease specific instrument). ${ }^{13}$ The EQ-5D gives scores varying from 1 (perfect health) to -0.59 (worst imaginable health state) and includes a visual analogue scale from 100 (perfect health) to 0 (worst imaginable 


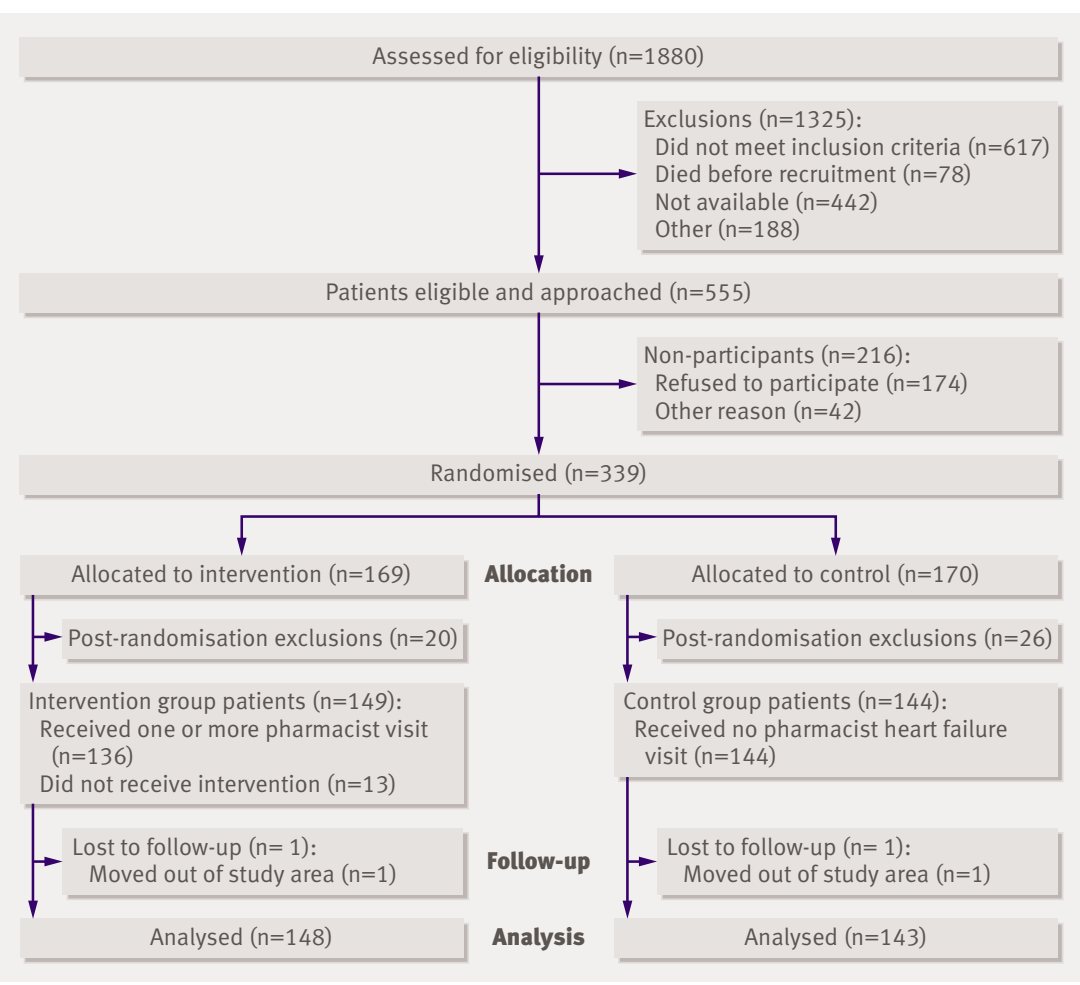

Fig 1 | Flow of patients through the study

health). The Minnesota living with heart failure questionnaire consists of 21 questions each scored from 0 to 5. Total scores thus vary from 0 to 105 , with higher scores implying a worse condition, and the questionnaire's authors consider a change of 5 points to be clinically significant. ${ }^{14}$ In addition, participants completed a questionnaire that measures drug adherence (medication adherence report scale or MARS; R Horne, personal communication, 2002) and the European heart failure self care behaviour scale. ${ }^{15}$ We introduced the last questionnaire as an additional measure eight months into recruitment. We also collected data on primary care activity, including numbers of home visits by general practitioners or nurses, practice attendances by patients, numbers of drugs prescribed, and telephone calls to or from patients.

Emergency admission data came from Hospital Episode Statistics. The Office for National Statistics provided mortality data. We mailed questionnaires up to three times to participants at three and six months, and the project coordinator contacted all patients before sending the questionnaires each time to maximise response. Because of resource constraints, we collected primary care data on a subgroup of trial patients (those within practices containing more than three trial patients).

We used Poisson regression to compare the number of readmissions between groups. We analysed mortality by using survival analysis comparing the two groups with the Cox proportional hazard ratio. In both analyses, we made adjustments for the two stratification variables (New York Heart Association class and recruitment site). We analysed questionnaire data at six months by using analysis of covariance, adjusting for baseline scores, New York Heart Association class, and recruitment site. We used Poisson regression to compare home visits by general practitioners and attendance at general practitioner practices, entering practices into the model as a random effect and adjusting for the two stratification variables.

We analysed patient data according to randomisation group, irrespective of whether or not they received the intervention as planned (the intention to treat principle). We used Stata version 8.0 and set statistical significance at the $5 \%$ level.

\section{Sample size calculation}

Local admission data suggested a rate of 0.6 admissions per heart failure patient within six months of discharge. Previous randomised controlled trials suggested that this could be reduced by $40 \%$ over six months - that is, from 0.6 to 0.36 admissions. ${ }^{716}$ Sample size calculations based on a normal approximation to the Poisson distribution indicated that we needed 306 patients to confer $80 \%$ power to show this reduction at the $5 \%$ significance level (two sided).

\section{RESULTS}

Participant flow and follow-up

Figure 1 shows the flow of patients through the trial. We approached a total of 555 patients to participate after screening them for eligibility between December 2003 and March 2005. We randomised the 339 (61\%) patients who agreed. We excluded 46 patients after randomisation because of death before discharge $(\mathrm{n}=18)$, heart failure diagnosis not confirmed $(\mathrm{n}=17)$, discharge to nursing/residential home $(n=7)$, planned cardiac surgery or terminal malignancy $(n=2)$, and previously recruited $(n=2)$. Table 1 shows that the two groups were similar at baseline, except that fewer intervention participants were from non-manual social classes $(44 \%$ v 55\%) and intervention participants more often used some form of drug adherence aid $(27 \% v 16 \%)$. Two patients moved out of the study area, so primary outcome data were available for 291 $(99 \%)$ patients.

Table 2 | Number of emergency hospital readmissions by group during six months' trial follow-up

\begin{tabular}{|c|c|c|c|c|c|c|c|c|c|}
\hline \multirow[b]{2}{*}{ Group } & \multicolumn{7}{|c|}{ No of readmissions over 6 months } & \multirow[b]{2}{*}{ Total admissions } & \multirow[b]{2}{*}{ Person years of follow-up } \\
\hline & 0 & 1 & 2 & 3 & 4 & 5 & 6 & & \\
\hline Control & 70 & 49 & 13 & 9 & 1 & 0 & 1 & 112 & 64.58 \\
\hline Intervention & 72 & 42 & 18 & 12 & 1 & 2 & 1 & 134 & 67.18 \\
\hline
\end{tabular}




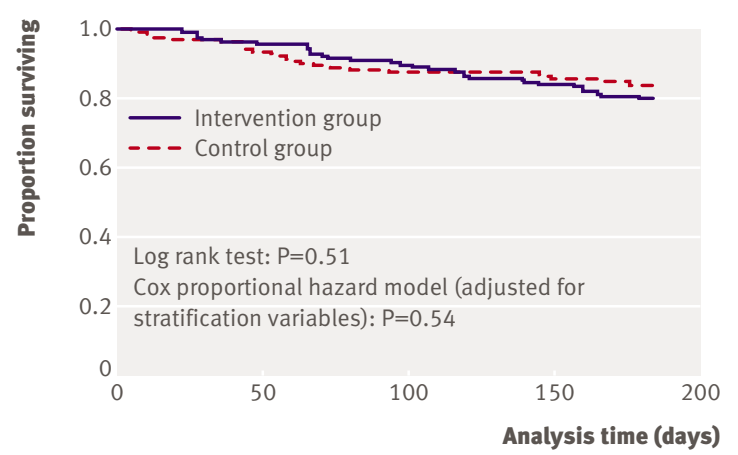

Fig 2 Kaplan-Meier graph showing time to death in intervention and control groups

\section{Study pharmacists and intervention visits}

We recruited 17 study pharmacists. Of 149 patients in the intervention group, $136(91 \%)$ received first visits. Seven $(5 \%)$ patients were unavailable for various reasons, including death or early readmission, and six $(4 \%)$ patients or their carers refused to be visited. Study pharmacists made a median of nine first visits each. Second visits were carried out for $119(80 \%)$ patients; most of the losses were the result of death or readmission. Pharmacists spent an average of 5 hours 53 minutes delivering each patient's intervention. This time was split reasonably evenly between visits (first visits mean length 72 minutes, second visits 50 minutes), administration (mean 114 minutes), and travel (mean 131 minutes). Pharmacists reported that they provided lifestyle advice (exercise, diet, and salt restriction advice) to more than $95 \%$ of visited patients and advice on symptom self management to all but one patient. Alcohol and smoking cessation advice were delivered to a lower proportion of patients, as few smoked $(n=6)$ or drank alcohol (median reported weekly alcohol intake $=0$ units). Visits generated a total of 384 recommendations to general practitioners (2.8/visited patient), 257 after first visits and 127 after second visits. Approximately one third of recommendations related to heart failure drugs or monitoring; the remainder generally referred to other drug advice or monitoring. Pharmacists reported that 131 (51\%) first visit recommendations were fully or partly enacted and $54(21 \%)$ were not enacted; no data were available on the remaining recommendations.

\section{Number of hospital readmissions}

A total of 112 emergency readmissions occurred in the control group and 134 in the intervention group (table 2). The Poisson model indicated a non-significant $15 \%$ increase in the intervention group's rate of readmission (rate ratio $=1.15,95 \%$ confidence interval 0.89 to $1.48 ; \mathrm{P}=0.28)$. Including social class and use of a drug adherence aid in the model, as these differed between groups at baseline, decreased the rate ratio slightly (rate ratio $=1.08,0.83$ to $1.40 ; \mathrm{P}=0.59$ ).

\section{Secondary outcomes}

Mortality-Mortality data were available for all patients. Fewer deaths occurred in the control group than in the intervention group (24 v 30). Figure 2 shows the Kaplan-Meier survival graph. The hazard ratio comparing intervention and control groups was 1.18 (95\% confidence interval 0.69 to $2.03 ; \mathrm{P}=0.54$ ).

Quality of life-EQ-5D scores at six months could be compared for 108 intervention patients and 104 controls $(91 \%$ of surviving intervention patients and $87 \%$ of surviving controls) (table 3). Whereas intervention patients' scores were unchanged, controls' scores decreased by 10\% (worsened), although the difference between groups was not significant (adjusted mean difference $=0.07,95 \%$ confidence interval -0.01 to 0.14 ; $\mathrm{P}=0.08)$. Scores on the visual analogue health scale improved slightly for both groups, but again did not differ significantly between groups. Minnesota living with heart failure questionnaires were completed by 78 intervention patients and 80 control patients at six months $(66 \%$ of surviving intervention patients and $67 \%$ of surviving controls). Whereas intervention patients' scores increased (worsened) slightly, those for control patients decreased (improved) slightly.

Table $3 \mid$ Mean EQ-5D scores, health visual analogue scale (VAS) scores, and Minnesota living with health failure questionnaire (MLHFQ) scores for groups at baseline and at three months' and six months' follow-up

\begin{tabular}{|c|c|c|c|c|c|}
\hline & \multicolumn{2}{|c|}{ Intervention group } & \multicolumn{2}{|c|}{ Control group } & \multirow[b]{2}{*}{ Adjusted mean difference $(95 \% \mathrm{Cl})$; $\mathrm{P}$ value* } \\
\hline & Score (SD) & $\begin{array}{c}\text { No of } \\
\text { respondents }\end{array}$ & Score (SD) & $\begin{array}{c}\text { No of } \\
\text { respondents }\end{array}$ & \\
\hline EQ-5D at baseline & $0.58(0.32)$ & 147 & $0.57(0.34)$ & 144 & \\
\hline EQ-5D at 3 months $\dagger$ & $0.54(0.33)$ & 113 & $0.51(0.37)$ & 100 & \\
\hline EQ-5D at 6 months $\dagger$ & $0.58(0.29)$ & 108 & $0.52(0.34)$ & 104 & $0.07(-0.01$ to 0.14$) ; P=0.08$ \\
\hline VAS at baseline $\dagger$ & $56.6(19.0)$ & 143 & $56.9(19.6)$ & 140 & \\
\hline VAS at 3 months $†$ & $58.4(20.8)$ & 107 & $52.9(21.9)$ & 96 & \\
\hline VAS at 6 months $†$ & $58.2(19.6)$ & 105 & $58.6(19.8)$ & 102 & $-0.93(-6.05$ to 4.20$) ; P=0.72$ \\
\hline MLHFQ at baselinef & $45.9(24.4)$ & 139 & $46.1(23.9)$ & 136 & \\
\hline MLHFQ at 3 months $\ddagger$ & $49.6(28.4)$ & 85 & $54.4(26.4)$ & 71 & \\
\hline MLHFQ at 6 months $\ddagger$ & $47.7(26.3)$ & 78 & $44.5(27.9)$ & 80 & $3.73(-3.67$ to 11.13$) ; P=0.32$ \\
\hline
\end{tabular}

*Based on analysis of covariance comparing results at six months adjusted for baseline score, site, and New York Heart Association class. †High scores imply better health.

fLow scores imply better health. 
Table 4 | Medication adherence report scale (MARS) scores

\begin{tabular}{|c|c|c|c|c|c|}
\hline \multirow[b]{2}{*}{ Time } & \multicolumn{2}{|c|}{ Intervention group $(n=149)$} & \multicolumn{2}{|c|}{ Control group $(n=144)$} & \multirow[b]{2}{*}{$\begin{array}{c}\text { Adjusted mean difference } \\
(95 \% \mathrm{Cl}) ; \mathrm{P}^{\text {value* }}\end{array}$} \\
\hline & $\begin{array}{c}\text { Mean } \\
\text { (median) }\end{array}$ & No of respondents & $\begin{array}{c}\text { Mean } \\
\text { (median) }\end{array}$ & $\begin{array}{c}\text { No of } \\
\text { respondents }\end{array}$ & \\
\hline Baseline & $23.82(25)$ & 133 & $23.64(25)$ & 127 & \\
\hline 3 months & $24.11(25)$ & 112 & $24.09(25)$ & 96 & \\
\hline 6 months & $23.74(25)$ & 101 & $23.55(25)$ & 103 & $\begin{array}{c}0.12(-0.48 \text { to } 0.73) \text { units; } \\
P=0.68\end{array}$ \\
\hline
\end{tabular}

Scores can range from 5 (very poor adherence) to 25 (perfect adherence).

*Analysis of covariance comparing results at six months adjusted for baseline score, site of recruitment, and New York Heart Association class.

This difference was not significant (adjusted mean difference $=3.73,-3.67$ to $11.13 ; \mathrm{P}=0.32$ ).

Drug adherence and behaviour change-Patients in both groups reported very high levels of adherence at all times of follow-up; no between group differences were evident. Final adherence scores were marginally higher (better) in the intervention group (adjusted mean difference $=0.12$ units, -0.48 to 0.73 units; $\mathrm{P}=0.68$ ) (table 4). Heart failure behaviour scores improved in both groups, although the final scores were non-significantly lower (better) in the intervention group (adjusted mean difference $=1.7$ units, -4.9 to 1.5 units, $\mathrm{P}=0.29$ ) (table 5).

Appropriateness of visit and patient satisfaction - Pharmacists considered that the first visit was definitely useful for $68(50 \%)$ patients and probably useful for 51 $(38 \%)$ patients; they considered second visits to be definitely useful for $37(31 \%)$ patients and probably useful for $58(49 \%)$. One hundred and two (82\% of those surviving) intervention patients responded to the satisfaction questionnaire at three months, of whom $75(74 \%)$ considered the visits to have been extremely or very useful.

Primary care data-We included 135 patients from 25 practices in this analysis (70 intervention patients, 65 controls). The intervention seemed to increase primary care activity both in the home and in the general practice surgery, and increased numbers of prescription items. However, with the exception of general practitioners' telephone calls and prescription items, differences between the groups were not statistically significant (table 6). Given these findings, we did one unplanned (post hoc) analysis, which summed all primary care activity (that is, all home visits, attendances at general practices, and phone calls). This analysis

Table 5 | European heart failure self care behaviour scale scores

\begin{tabular}{|c|c|c|c|c|c|}
\hline \multirow[b]{2}{*}{ Time } & \multicolumn{2}{|c|}{ Intervention group $(n=149)$} & \multicolumn{2}{|c|}{ Control group $(n=144)$} & \multirow[b]{2}{*}{$\begin{array}{l}\text { Adjusted mean difference } \\
(95 \% \mathrm{Cl}) ; \mathrm{P}^{\text {value }}\end{array}$} \\
\hline & Score (SD) & $\begin{array}{l}\text { No of } \\
\text { respondents }\end{array}$ & Score (SD) & $\begin{array}{l}\text { No of } \\
\text { respondents }\end{array}$ & \\
\hline Baseline & $31.1(8.69)$ & 90 & $30.6(9.07)$ & 80 & \\
\hline 3 months & $26.08(10.04)$ & 60 & $26.58(10.47)$ & 50 & \\
\hline 6 months & $26.58(9.45)$ & 60 & $28.27(8.66)$ & 52 & $\begin{array}{c}-1.7(-4.9 \text { to } 1.5) \text { units; } \\
\mathrm{P}=0.29\end{array}$ \\
\hline
\end{tabular}

This questionnaire was included from the mid point of the study, so data are available on only a subset of participants; scores can range from 12 to 60; low scores imply better self care behaviour.

*Analysis of covariance comparing results at six months adjusted for baseline score, site of recruitment, and New York Heart Association class. suggested that the intervention led to a $17 \%$ increase in primary care activity (rate ratio $=1.17,95 \%$ confidence interval 1.06 to $1.29 ; \mathrm{P}=0.002$ ).

\section{DISCUSSION}

\section{Principal findings of the study}

The results suggest that this community pharmacist intervention does not lead to reductions in hospital admissions, in contrast to those found in trials of specialist nurse led interventions in heart failure. ${ }^{1}$ Instead, the intervention may increase emergency hospital admissions, although this result was not statistically significant. Equally, the intervention seemed to lead to a concomitant increase in primary care activity.

In terms of secondary outcomes, the intervention had no clear effect on mortality, although deaths were greater in number in the intervention group. The intervention led to no clear improvement in quality of life or drug adherence; we saw some indication of improved self care, but changes were not statistically significant.

\section{Strengths and weaknesses of the study}

We believe that the internal validity of this study was high, with concealed allocation of randomisation, both groups reasonably equivalent at baseline (with the exception of differences in social class and use of a medication adherence aid), and good follow-up of patients (99\% for the primary outcome). However, patients could not be blinded to treatment group, which may have biased their responses to questionnaires. The trial deliberately used a large number of pharmacists and broad inclusion criteria to ensure its generalisability.

\section{Strengths and weaknesses in relation to other studies} Most non-pharmacological trials in heart failure have tended to be small (median 180 patients). ${ }^{1}$ By comparison, this study was larger $(\mathrm{n}=293)$. Early meta-analyses in this area suggested that reductions of $25-40 \%$ in admissions might be possible. ${ }^{1718}$ However, more recent meta-analyses, published after this trial started, have suggested that such interventions yield more modest reductions in admissions of approximately 10$20 \% .^{1}$ This trial did not have a sample size based on this smaller effect. Our confidence limit around the main outcome, however, suggests that at best our intervention could lead to either a small decrease $(10 \%)$ or a potentially substantial increase $(50 \%)$ in admissions.

Despite these problems related to sample size, the finding that the intervention at best had no clear positive effect did seem to be consistent. Instead, it would seem to have increased health service activity in both secondary and primary care with no comparable health improvement (as measured by quality of life and mortality). The intervention, although appreciated by patients, affected their heart failure "self care" only modestly, if at all. Little gain seemed to be made in adherence, as patients reported very good adherence even at baseline, although such self report data should be considered with some caution. ${ }^{19}$ Finally, the two quality of life measures seemed to move in different 
directions, with small gains suggested by the EQ-5D that were not replicated by the Minnesota living with heart failure questionnaire.

\section{Meaning of the study}

One may conjecture about possible explanations for our failure to detect a positive effect size as large as $40 \%$ seen in some studies. One possible explanation is that the intervention was not delivered as intended. This seems unlikely, as pharmacists reported delivering all components of the intervention and this was corroborated by the substudy, which recorded a sample of interventions and identified that each component was indeed delivered. ${ }^{10}$ The substudy also suggested that the pharmacists seemed to use good consultation styles, as measured by the Henbest and Stewart rating scale. ${ }^{20}$ Furthermore, the visits seemed to be well received by patients, almost all of whom considered them to have been useful and of the right length and that the pharmacists had an appropriate level of knowledge. Nevertheless, a good communication style alone is unlikely to be sufficient. Indeed, the intervention was reasonably brief, and further research is needed to examine whether more focused interviewing skills of motivating behavioural change or promoting shared decision making would improve outcomes for patients. ${ }^{2122}$

Our intervention may also have been too late in the disease course to evoke behaviour change. This study included a broad mix of heart failure patients, and many patients may have already made changes to their behaviour (such as stopping smoking). Equally, others may have already adapted their lifestyle to their diagnosis (for example, by reducing their exercise), which potentially would have made them more resistant to accepting advice. A recent study of a specialist nurse led intervention also found no overall effect, but suggested possible effectiveness in newly diagnosed patients. ${ }^{23}$

\begin{tabular}{|c|c|c|c|c|}
\hline & $\begin{array}{l}\text { Intervention } \\
\text { group }(n=70)\end{array}$ & $\begin{array}{l}\text { Control } \\
\text { group } \\
(n=65)\end{array}$ & Rate ratio* & Adjusted rate ratio $\dagger$ \\
\hline GP home visits & 134 & 99 & 1.28 (0.97 to 1.68$) ; P=0.08$ & $\begin{array}{c}1.03(0.77 \text { to } 1.37) ; \\
P=0.83\end{array}$ \\
\hline Nurse/other visit & 84 & 67 & 1.13 (0.82 to 1.57$) ; P=0.46$ & $\begin{array}{c}1.05(0.75 \text { to } 1.47) ; \\
P=0.76\end{array}$ \\
\hline $\begin{array}{l}\text { Practice attendance- } \\
\text { GP }\end{array}$ & 289 & 263 & 1.05 (0.88 to 1.26$) ; P=0.56$ & $\begin{array}{c}1.09(0.90 \text { to } 1.30) ; \\
P=0.37\end{array}$ \\
\hline $\begin{array}{l}\text { Practice attendance- } \\
\text { nurse/other }\end{array}$ & 373 & 316 & 1.13 (0.96 to 1.33 ); $P=0.13$ & $\begin{array}{c}1.12(0.95 \text { to } 1.32) ; \\
P=0.19\end{array}$ \\
\hline $\begin{array}{l}\text { GP phone calls to/from } \\
\text { patient }\end{array}$ & 109 & 69 & 1.62 (1.17 to 2.23 ); $\mathrm{P}=0.003$ & $\begin{array}{c}1.54(1.11 \text { to } 2.13) ; \\
P=0.01\end{array}$ \\
\hline $\begin{array}{l}\text { Nurse/other phone call } \\
\text { to/from patient }\end{array}$ & 74 & 35 & 1.80 (1.17 to 2.75 ); $\mathrm{P}=0.007$ & $\begin{array}{c}1.54 \text { (0.98 to } 2.42) ; \\
P=0.06\end{array}$ \\
\hline $\begin{array}{l}\text { Mean (median) drugs } \\
\text { prescribed over } \\
6 \text { months }\end{array}$ & $47.0(41)$ & $41.0(38)$ & 1.12 (1.06 to 1.18 ); P<0.001 & $\begin{array}{c}1.08(1.02 \text { to } 1.14) ; \\
P=0.005 \ddagger\end{array}$ \\
\hline \multicolumn{5}{|c|}{$\begin{array}{l}\text { GP=general practitioner. } \\
\text { *Participants' general practice entered as random effect. } \\
\text { †Adjusted for hospital site of recruitment and New York Heart Association Class (stratification variables). } \\
\ddagger \text { Additionally adjusted for number of drugs prescribed at baseline. }\end{array}$} \\
\hline
\end{tabular}

Finally, the pharmacists were not specialists in heart failure care. Their experience and training in heart failure were thus necessarily more limited than those of specialist heart failure nurses. In particular, they were not trained to titrate drugs such as low dose $\beta$ blockers, which has been a feature of the most recent multidisciplinary interventions. ${ }^{24}$ This specialist versus generalist distinction may be important when considering interventions in heart failure. This is supported by a recent meta-analysis, which identified that outcomes were most favourable when interventions were delivered by a multidisciplinary specialist cardiac team at home or in the clinic. ${ }^{25}$

\section{Unanswered questions and future research}

The non-significant findings in this study mean that definitive conclusions are not possible. The confidence interval around our primary outcome can not exclude our intervention causing a modest decrease in admissions. However, the consistency of the results across the variety of study outcomes suggest that community pharmacists have no clear effect and may potentially increase use of health services. This last possibility was previously suggested by the HOMER trial, also done by our group. ${ }^{8}$ In contrast to this trial, HOMER recruited older patients with any disease. However, although our HeartMed intervention was focused on heart failure, pharmacists also gave advice and recommendations on patients' complete drug regimen, and indeed over half of their recommendations to general practitioners related to other conditions. Thus, this trial adds further evidence to suggest that drug review type interventions may not necessarily yield positive health service gains, even when they are focused on one disease area. ${ }^{26}$ Whether a more intense version of our intervention could have yielded more positive effects is unknown. Equally, other examples exist of interventions that seem to have the potential to decrease health service activity but in reality may not affect it (such as the experience of NHS Direct ${ }^{27}$ ) or may even increase use. ${ }^{28}$ Such interventions, although often appreciated by patients, may simply lower the threshold for seeking medical advice, increasing the cost of health care without concomitant improvements in health.

Given that heart failure accounts for 5\% of hospital admissions, these results present a problem for policy makers who are faced with a shortage of specialist provision yet desire services that are widely available and can reduce admissions. The next research steps should be to rigorously evaluate whether initiatives to deliver specialist care across larger geographical areas have been successful, ${ }^{29}$ but also to determine how intense such services need to be.

We thank Annie Blyth, Vivienne Maskrey, Bett Barrett, Julia Hill, Jane TrippettJones, Jeanette Blacklock, and Lisa Regan for their hard work recruiting patients collecting data. We thank Catherine Heywood, clinical pharmacist, Norfolk and Norwich University Hospital (NNUH); Janis Riches, Norwich PCT smoking cessation adviser; Esmarie Van Tonder, senior community dietitian, NNUH; Janice Nash, physiotherapist, NNUH; Phillip Ralphs (patient representative); and Toni Hardiman, cardiology specialist nurse, NNUH, for delivering the heart failure 


\section{WHAT IS ALREADY KNOWN ON THIS TOPIC}

Educational and symptom self management interventions can decrease mortality and readmissions in heart failure patients when delivered by specialist personnel

Specialist staff to deliver such interventions are in short supply

\section{WHAT THIS STUDY ADDS}

Patients were very satisfied with an educational and symptom self management intervention delivered by community pharmacists

This intervention did not lead to reductions in admissions or mortality of the magnitude seen with specialist interventions

Community pharmacists may not with current training be sufficiently expert to deliver the type of intervention needed to reduce heart failure admissions and mortality

training for the participating community pharmacists and Richard Youngs, Chris Abell, and Alexia Papageorgiou, UEA, for providing communication skills training for the community pharmacists. We also thank all the participating pharmacists, Norfolk Local Pharmaceutical Committee, and the study participants.

Contributors: RH, EL, IH, LS, and RS designed the study. RH, LH, EL, and KA analysed the results. All authors interpreted the results and contributed to writing revisions and approved the final manuscript. RH is the guarantor. Funding: Research costs were funded by a project grant from the British Heart Foundation. Excess treatment costs were funded by Great Yarmouth and Southern Norfolk Primary Care Trusts. This trial received support for the educational training events from Pfizer UK.

Competing interests: None declared.

Ethical approval: Norwich District, King's Lynn, and Great Yarmouth and Waveney local research ethics committees.

1 Holland R, Battersby J, Harvey I, Lenaghan E, Smith J, Hay L. Systematic review of multidisciplinary interventions in heart failure. Heart 2005;91:899-906.

2 Blue L, Lang E, McMurray II, Davie AP, McDonagh TA, Murdoch DR, et al. Randomised controlled trial of specialist nurse intervention in heart failure. BMJ 2001;323:715-8.

3 Department of Health. Choosing health through pharmacyprogramme for pharmaceutical public health 2005-2015. London: Department of Health, 2005.

4 Coggans N, McKellar S, Bryson S, Parr RGL. Evaluation of health promotion development in Greater Glasgow Health Board community pharmacies. Pharmaceutical Journal 2001;266:514-8.

5 Sinclair HK, Bond CM, Lennox AS, Silcock J, Winfield AJ, Donnan PT. Training pharmacists and pharmacy assistants in the stage-ofchange model of smoking cessation: a randomised controlled trial in Scotland. Tob Control 1998;7:253-61.

6 Goodyer LI, Miskelly F, Milligan P. Does encouraging good compliance improve patients' clinical condition in heart failure? $\mathrm{Br}$ Clin Pract 1995;49:173-6.

7 Varma S, McElnay JC, Hughes CM, Passmore AP, Varma M. Pharmaceutical care of patients with congestive heart failure: interventions and outcomes. Pharmacotherapy 1999:19:860-9.

8 Holland R, Lenaghan E, Harvey I, Smith R, Shepstone L, Lipp A, et al. Does home based medication review keep older people out of hospital? The HOMER randomised controlled trial. $B M$ 2005;330:293.

9 British Heart Foundation. Living with heart failure. London: British Heart Foundation, 2004. (Heart Information Series No 8.)
10 Greenwood K, Howe A, Holland R. The use of consultation skills assessment tools in pharmacist-patient consultations. Int J Pharm Pract 2006;14:277-82.

11 Rabin R, de Charro F. EQ-5D: a measure of health status from the EuroQol Group. Ann Med 2001;33:337-43.

12 Holland R, Smith RD, Harvey I, Swift L, Lenaghan E. Assessing quality of life in the elderly: a direct comparison of the EQ-5D and AQoL. Health Econ 2004;13:793-805.

13 Rector TS, Cohn JN. Assessment of patient outcome with the Minnesota living with heart failure questionnaire: reliability and validity during a randomized, double-blind, placebo-controlled trial of pimobendan. Am Heart J 1992;124:1017-25.

14 Rector TS, Tschumperlin LK, Kubo SH, Bank AJ, Francis GS, McDonald KM, et al. Use of the living with heart failure questionnaire to ascertain patients' perspectives on improvement in quality of life versus risk of drug-induced death. J Card Fail 1995;1:201-6.

15 Jaarsma T, Stromberg A, Martensson J, Dracup K. Development and testing of the European heart failure self-care behaviour scale. Eur J Heart Fail 2003;5:363-70.

16 Stewart S, Pearson S, Horowitz ID. Effects of a home-based intervention among patients with congestive heart failure discharged from acute hospital care. Arch Intern Med 1998;158:1067-72.

17 Rich MW. Heart failure disease management: a critical review. J Card Fail 1999;5:64-75.

18 Phillips CO, Wright SM, Kern DE, Singa RM, Shepperd S, Rubin HR. Comprehensive discharge planning with postdischarge support for older patients with congestive heart failure: a meta-analysis. JAMA 2004;291:1358-67.

19 Rickels K, Briscoe E. Assessment of dosage deviation in outpatient drug research. J Clin Pharmacol J New Drugs 1970;10:153-60.

20 Henbest RJ, Stewart MA. Patient-centredness in the consultation. 1: A method for measurement. Fam Pract 1989;6:249-53.

21 Botelho R. Motivational practice: a resource guidebook for skills development. Rochester, NY: MHH Publications, 2004.

22 Elwyn G, Edwards A, Kinnersley P, Grol R. Shared decision making and the concept of equipoise: the competences of involving patients in healthcare choices. Br J Gen Pract 2000;50:892-7.

23 Zaphirou A, Mulligan K, Hagrave P, Patterson D, Cowie M, Newman S, et al. Improved outcomes following hospitalisation in patients with a new diagnosis of heart failure: results from a randomised controlled trial of a novel nurse-led self-management intervention. Heart 2006;92(II):A119.

24 Cleland JG, Louis AA, Rigby AS, Janssens U, Balk AH. Noninvasive home telemonitoring for patients with heart failure at high risk of recurrent admission and death: the trans-European network-homecare management system (TEN-HMS) study. J Am Coll Cardiol 2005;45:1654-64.

25 McAlister FA, Stewart S, Ferrua S, McMurray JJ. Multidisciplinary strategies for the management of heart failure patients at high risk for admission: a systematic review of randomized trials. J Am Coll Cardiol 2004;44:810-9.

26 Community Pharmacy Medicine Management Project Evaluation Team. The MEDMAN study: a randomized controlled trial of community pharmacy-led medicines management for patients with coronary heart disease. Family Practice 2007 (advance access doi:10.1093/fampra/cm1075)

27 Munro J, Sampson F, Nicholl J. The impact of NHS Direct on the demand for out-of-hours primary and emergency care. Br J Gen Pract 2005;55:790-2.

28 Weinberger M, Oddone EZ, Henderson WG. Does increased access to primary care reduce hospital readmissions? N Engl J Med 1996;334:1441-7.

29 British Heart Foundation. Heart failure nurses. www.bhf.org.uk living_with_heart_conditions/patient_support_resources/ heart_nurses/heart_failure_nurses.aspx.

Accepted: 8 March 2007 